\title{
PHƯƠNG THỨC TIẾP CÂNN HIÊN THỰC TRONG TÁC PHẨM CỦA VŨ TRỘNG PHỤNG DƯớI GÓC NHÌN CHỦ NGHĨA HIỆN ĐẠI
}

\author{
Kiều Thanh Uyên ${ }^{a^{*}}$ \\ ${ }^{a}$ Khoa Ngũ văn và Văn hóa học, Trường Đại học Đà Lạt, Lâm Đồng, Việt Nam \\ *Tác giả liên hệ: Email: uyenkt@dlu.edu.vn \\ Lịch sử bài báo \\ Nhận ngày 05 tháng 11 năm 2018 \\ Chỉnh sửa ngày 23 tháng 11 năm 2018 | Chấp nhận đăng ngày 26 tháng 11 năm 2018
}

\section{Tóm tắt}

Vũ Trọng Phụng là một trong nhũng nhà văn sớm tiếp nhận chủ nghĩa hiện đại. Điều này cho thấy ý thức tiếp nhận cũng nhu nỗ lục cập nhật nhũng trào lưu tu tuởng hiện đại, thời thượng nhằm bắt kịp xu huớng văn học thê giới của nhà văn này vào nửa đầu thế kỷ $X X$. Bài nghiên cứu này khảo sát và phân tích phưong thức tiếp cận hiện thưc theo trào lưu hiện đại chủ nghĩa trong tác phẩm của Vũ Trọng Phung. Trên cơ sở đó, bài viết huớng đến khẳng định Vũ Trọng Phụng là một trong nhũng nhà văn tiên phong tiếp thu chủ nghĩa hiện đại của văn học phuơng Tây, cũng nhu góp tiếng nói khăng định về tài năng và phong cách của nhà văn này trong tiến trình văn học Việt Nam.

Từ khóa: Chủ nghĩa hiện đại; Phương thức tiếp cận hiện thực; Vũ Trọng Phụng.

Mã số định danh bài báo: http://tckh.dlu.edu.vn/index.php/tckhdhdl/article/view/519

Loại bài báo: Bài báo nghiên cứu gốc có bình duyệt

Bản quyền @ 2018 (Các) Tác giả.

Cấp phép: Bài báo này được cấp phép theo CC BY-NC-ND 4.0 


\title{
THE APPROACHES TO REALITY IN VŨ TRỌNG PHỤNG'S WORKS FROM MODERNISM VIEWPOINT
}

\author{
Kieu Thanh Uyen ${ }^{a^{*}}$ \\ ${ }^{a}$ The Faculty of Literature and Cultural Studies, Dalat University, Lamdong, Vietnam \\ *Corresponding author: Email: uyenkt@dlu.edu.vn \\ Article history \\ Received: November $05^{\text {th }}, 2018$ \\ Received in revised form: November $23^{\text {rd }}, 2018$ | Accepted: November $26^{\text {th }}, 2018$
}

\begin{abstract}
Vũ Trong Phung is one of the earliest modernist writers in Vietnamese literature. This shows his receptiveness to modern trends as well as his attempts to update Vietnamese literature to catch up with trends in world literature in the first half of the twentieth century. This paper examines and analyzes the approaches to reality in the works of Vũ Trong Phung. On this basis, the paper demonstrates that Vũ Trong Phung was an advanced Vietnamese writer who absorbed Western literary modernism. Also, the paper offers affirmation of the significant position of this writer in the progress of Vietnamese literature in terms of his distinguished talent and style.
\end{abstract}

Keywords: Modernism; The approaches to reality; Vũ Trọng Phụng.

Article identifier: http://tckh.dlu.edu.vn/index.php/tckhdhdl/article/view/519

Article type: (peer-reviewed) Full-length research article

Copyright (C) 2018 The author(s).

Licensing: This article is licensed under a CC BY-NC-ND 4.0 


\section{PHƯƠNG THỨC TIẾP CẬN HIỆN THỰC THEO TRÀO LUUU HIỆN ĐẠI CHỦ NGHĨA VÀ TÁC PHẨM CỦA VŨ TRỌNG PHỤNG}

\subsection{Phương thức tiếp cận hiện thực theo trào lưu hiện đại chủ nghĩa}

Phương thức tiếp cận hiện thực (the approaches to reality) của nhà văn Vũ Trọng Phụng được thể hiện thông qua hình tượng nhân vật, cốt truyện, điểm nhìn trần thuật trong tác phẩm. Nói cách khác, đó là thế giới nghệ thuật trong tác phẩm mà nhà văn tái hiện thông qua việc quan sát hiện thực. Phương pháp tiếp cận hiện thực sẽ chịu sự chi phối của trào lưu văn học. Nếu chủ nghĩa cổ điển có cách thức tiếp cận hiện thực mang tính quy phạm và đề cao tư duy duy lý, thì chủ nghĩa lãng mạn đề cao tính chủ quan, cách xa thực tại. Ngược lại, chủ nghĩa hiện thực nhấn mạnh óc quan sát, phân tích, lý giải hiện thực, đề cao vai trò yếu tố hoàn cảnh. Trong khi đó, chủ nghĩa tự nhiên lại chú trọng mô tả đời sống tâm sinh lý con người như một hiện tượng tự nhiên.

Đối với chủ nghĩa hiện đại, phương thức tiếp cận hiện thực theo tinh thần cơ bản "Làm mới nó" (Make it new) ${ }^{1}$ (Dettmar, 2006, tr. 1). Bởi vì, thời điểm chủ nghĩa hiện đại xuất hiện gần như đồng thời với tư duy duy lý của thời đại Khai sáng mất đi chỗ đứng, hệ thống niềm tin, thế giới quan ở trạng thái bão hòa. Chủ nghĩa hiện đại xuất hiện như một nhu cầu thay đổi, cách tân, đổi mới tự thân để tìm kiếm những hình thức biểu đạt mới trong văn học nghệ thuật vào cuối thời hiện đại. Mặc dù, chủ nghĩa hiện đại vẫn nằm trong khuôn mẫu truyền thống của thời hiện đại với chủ nghĩa lãng mạn, chủ nghĩa hiện thực nhưng cũng có những sáng tạo hướng tới cái mới và đề xuất sự phá cách trong văn học nghệ thuật.

Bối cảnh tàn phá của hai cuộc chiến tranh lớn cùng với sự phát triển của khoa học kỹ thuật ảnh hưởng trực tiếp đến đời sống xã hội và văn hóa của con người. Đồng thời, hệ thống niềm tin, thế giới quan, nhân sinh quan cũng bị lung lay đến tận gốc rễ và thế giới quan khoa học đã mở ra một thế giới mới đối với con người. Do đó, chủ nghĩa hiện đại trong văn học chủ yếu tiếp cận hiện thực qua tính phi hài hoà của thế giới, tính phi nhân trong xã hội thực tại, sự tha hoá của cá nhân, tình trạng mất tự do, chống truyền thống, chống chủ nghĩa quy phạm. Vì vậy, đặc điểm thường thấy trong các tác phẩm văn học hiện đại chủ nghĩa là hiện thực tàn khốc, phi lý, các mâu thuẫn không thể giải quyết, con người cô đơn tuyệt vọng, thù địch với hoàn cảnh, màu sắc ảm đạm, tâm trạng bi quan, thái độ hoài nghi, bi kịch của sự tự tha hoá, tự huỷ hoại. Chủ nghĩa hiện đại còn nhấn mạnh sự phản ánh hiện thực toàn diện kể cả phần bản năng, vô thức của con người cũng như khám phá bản chất sâu xa, bí ẩn đằng sau bề mặt của hiện thực.

Đối với phương thức tiếp cận hiện thực theo trào lưu hiện đại chủ nghĩa trong văn học, ngoài phong cách trần thuật "gián tiếp tự do", "đối thoại bên trong", nổi bật nhất là thủ pháp dòng ý thức, mô hình tự sự ẩn ý - tượng trưng và thủ pháp cắt dán điện

\footnotetext{
${ }^{1}$ Theo Dettmar (2006) trong Lời giới thiệu cho cuốn sách A Companion to Modernist Literature and Culture, "Make it new" là lời kêu gọi bởi nhà thơ Hiện đại chủ nghĩa Ezra Pound - hạt nhân trong sự sáng tạo thẩm mỹ của Chủ nghĩa Hiện đại. Ezra Pound thừa nhận câu nói đó là do một hoàng đế Trung Hoa khắc lên bồn tắm của mình.
} 
ảnh. Thủ pháp dòng ý thức được biết đến qua tiểu thuyết nổi tiếng Đi tìm thời gian đã mất (À la recherche du Temps perdu) của tiều thuyết gia người Pháp Marcel Proust.

\subsection{Tác phẩm của Vũ Trọng Phụng}

Về nghệ thuật tiếp cận hiện thực của Vũ Trọng Phụng, Vương (1990, tr. 162) khẳng định, "Trong khi chiếm lĩnh khách quan, văn chương của ông vẫn chủ quan đến từng chi tiết. Dù viết về cái gì ông cũng tìm ra được lý do để mang được cách giải thích nhân sinh của mình vào đó, và tạo ra đủ cớ để cho người ta phê phán ông là định mệnh, cay nghiệt, và cả khiêu dâm nữa". Hiện thực trong tác phẩm của Vũ Trọng Phụng còn là sự lắp ghép từ bối cảnh xã hội, môi trường sống của nhà văn kết hợp với cảm quan lịch sử. Hơn nữa, phương thức tiếp cận hiện thực của Vũ Trọng Phụng không chỉ là tái hiện mà còn bóp méo, đập vỡ, xáo trộn và lắp ghép lại theo ý muốn chủ quan, Zinoman (2001, tr. 18$)$ cũng cho rằng:

Số đỏ cũng bày tỏ một chuỗi các cảm giác tương đối phổ biến - một tri giác thành thị, một định hướng quốc tế chủ nghĩa, một nỗi hoài nghi ngày càng tăng về sự trong sáng và độ đáng tin cậy của ngôn ngữ, đồng thời những cảm giác châm biếm và bất lực ngày càng cao hơn - có liên quan đến những thay đổi nhanh chóng và bất ngờ, đặc trưng của thời hiện đại nói chung.

Trong các tác phẩm văn học trung đại, kể cả hiện đại như tiểu thuyết Tự Lực Văn Đoàn và một số tác phẩm văn xuôi hiện thực, thường có sự phân chia tuyến nhân vật. Tuyến nhân vật trong tiểu thuyết Tự Lực Văn Đoàn được phân chia rõ ràng, gồm tuyến nhân vật đại diện cho văn minh, tiến bộ và tuyến nhân vật đại diện cho truyền thống, phong kiến, cổ hủ. Chẳng hạn như cô Loan (Đoạn tuyệt) là nạn nhân của quy tắc truyền thống, cổ hủ của bà Phán. Thay vào đó, thế giới nhân vật trong tác phẩm của Vũ Trọng Phụng không thể phân biệt được tốt và xấu, nạn nhân hay thủ phạm. Ban đầu, Thị Mịch (Giông tố) là nạn nhân nhưng sau đó cũng chính cô tự đẩy mình vào sự tha hóa. Hay như Xuân Tóc Đỏ (Số đỏ), thật khó để khẳng định Xuân là tên lưu manh, lừa lọc hay là nạn nhân bị lợi dụng bởi gia đình Văn Minh, nói cách khác là nạn nhân của xã hội "chó đểu". Điều này ít nhiều chứng tỏ Vũ Trọng Phụng đã thoát khỏi khuôn mẫu văn học trung đại cũng như những quy phạm của chủ nghĩa lãng mạn và chủ nghĩa hiện thực.

Ngoài ra, dựa trên cơ sở những công trình của các nhà nghiên cứu đi trước và văn bản tác phẩm, chúng tôi cho rằng nghệ thuật tiếp cận hiện thực theo trào lưu hiện đại chủ nghĩa trong tác phẩm của Vũ Trọng Phụng biểu hiện qua hai yếu tố mô hình tự sự ẩn ý - tượng trưng và thủ pháp cắt dán điện ảnh.

\section{MÔ HÌNH TỰ SỰ ẨN Ý - TƯợNG TRƯNG}

Theo Đỗ (2015, tr. 212) trong bài nghiên cứu Vận dụng lí thuyết tư sư học vào nghiên cưu hình thái thể loại tiểu thuyết, "Hình thái cụ thể của tiểu thuyết nằm ở văn bản, thông qua phương thức trần thuật và thể thức ngôn ngữ của văn bản mà hiện ra". Mô hình trần thuật của tác phẩm tự sự chính là kết quả của quá trình tiếp cận hiện thực 
của nhà văn. Phân tích về mô hình tự sự của tiểu thuyết cho thấy được sự biến đổi những đặc điểm trần thuật qua các trào lưu, trường phái, tức là theo chiều lịch đại. Nhà nghiên cứu Dương Tinh Anh căn cứ vào sự vận động biến đổi của phương thức trần thuật đề chỉ ra sự vận động của hình thái thể loại tiểu thuyết:

Chẳng hạn, ở phương Tây từ trung thế kỷ đến thế kỷ XVIII, tiểu thuyết chuyển từ chú trọng cốt truyện sang khắc họa nhân vật, miêu tả tình tiết, hoàn cảnh. Đến thế kỷ XIX, với Dostoievski, không gian trần thuật được khai phá, người trần thuật biết hết vị phá vỡ, sử dụng điểm nhìn đa chiều, chuyển từ miêu tả bên ngoài sang miêu tả bên trong nhân vật... (trích trong Đô̂, 2015, tr. 213).

Theo Lê và Nguyễn $(2015$, tr. 37) trong bài nghiên cứu Dẫn luận về tư sự học của Susanna Onega và J.A. García Landa, việc phân tích tác phẩm tự sự thuộc mỹ học hiện thực thường chú ý đến các khái niệm như cốt truyện (plot), tính cách nhân vật (character), bối cảnh (setting), chủ đề (theme), mục đích đạo đức (moral aim) và vẻ giống như thực (versi militude). Còn đối với mô hình tự sự theo trào lưu hiện đại chủ nghĩa, "Một tác phẩm trước hêt là một mẫu hình (pattern) các từ, một thực thể tự túc, tự mình xây dựng và vận hành các tình cảm và tư tưởng, chỉ có một mối quan hệ giống nhau đối với thực tại”.

Nghiên cứu về mô hình trần thuật trong tác phẩm Vũ Trọng Phụng để thấy được mức độ tiếp nhận trào lưu hiện đại chủ nghĩa là điều cần thiết. Mặt khác, qua phân tích mô hình trần thuật có thể nắm bắt và khái quát hóa được phương thức tiếp cận hiện thực của Vũ Trọng Phụng khi vận dụng chủ nghĩa hiện đại.

Như chúng ta đã biết, khuynh hướng chính trong các tác phẩm của Vũ Trọng Phụng là chủ nghĩa hiện thực. Theo Lê và Nguyễn (2015), mô hình tự sự theo trào lưu chủ nghĩa hiện thực là mô hình cốt truyện - tính cách. Sự kiến tạo của mô hình tự sự này gồm ba nhân tố là cốt truyện, tính cách và hoàn cảnh. Đỗ (2015) cho rằng mô hình cốt truyện - tính cách này đã đưa đến kết quả là "cốt truyện của tiểu thuyết thể hiện quan hệ nhân quả của sự kiện và lịch sử tính cách nhân vật (vì hành động nhân vật quyết định tính cách nhân vật). Mô hình này nghiêng sang khắc họa sự li kì gấp khúc của cốt truyện và tính cách nhân vật" (Đỗ, 2015, tr. 215). Theo đó, mô hình tự sự này không chú trọng khám phá thế giới nội tâm nhân vật mà phản ảnh tính cách và sự kiện.

Những khuyết điểm của mô hình tự sự cốt truyện - tính cách đã được Vũ Trọng Phụng bù đắp bằng mô hình tự sự của trào lưu hiện đại chủ nghĩa. Qua khảo sát tác phẩm, có thể thấy, Vũ Trọng Phụng không sử dụng mô hình tự sự tâm lí - tinh thần mô hình tiêu biểu của tiểu thuyết dòng ý thức theo trào lưu hiện đại chủ nghĩa, mà ứng dụng mô hình tự sự ẩn ý - tượng trưng. Theo Đỗ $(2015$, tr. 218), mô hình ẩn ý - tượng trưng có thể hiểu như sau: "Tượng trưng là lấy hình tượng cụ thể riêng biệt để biểu hiện hoặc ám thị một quan niệm, triết lý, tình cảm. Trong lĩnh vực tiểu thuyết, hình tượng riêng biệt hoặc hệ thống hình tượng trong văn bản một bộ tiểu thuyết có thể là tượng trưng cho một quan niệm, triết lý”. 
Trong tiểu thuyết $S o ̂ ́$ đỏ, các hình tượng nhân vật đều được Vũ Trọng Phụng xây dựng nhằm tượng trưng cho xã hội chạy theo làn sóng Âu hóa, quay cuồng theo đồng tiền, ưa phỉnh nịnh và háo danh vọng. Chẳng hạn như ông Văn Minh đi du học nhưng không có bằng cấp lại cổ vũ cải cách thời trang, ủng hộ phong trào thể thao. Ông TYPN, nhà mỹ thuật Đông Dương biện minh cho phong trào cải cách thời trang hợm hĩnh là do "Chỉ vì trình độ thấp kém của xã hội mà anh em nghệ sĩ chúng tôi phải quay về làm cái việc cải cách y phục phụ nữ là món mỹ thuật dễ hiểu nhất. Bao giờ cả cái xã hội này biểt thưởng thức cái đẹp về bộ vú, bộ đùi của người đàn bà thì mới hiểu giá trị của những bức vẽ khỏa thân, và do thế, mới hiểu nổi những món mỹ thuật tối cao" (Vũ, 2014, tr. 61). Những tay nhà báo lại cổ vũ phong trào Âu hóa bằng cách: "Bao nhiêu vụ ly dị! Bao nhiêu cuộc ngoại tình! Con gái theo giai đùng đùng, đàn ông chê vợ hàng lũ, lại vừa có cả một ông huyện treo ấn từ quan để theo một cô gái tân thời, như thế, tôi tưởng là báo chúng tôi có ảnh hưởng quá nữa!" (Vũ, 2014, p. 70). Cô Hoàng Hôn chạy theo bình quyền "Có chồng thôi mà không có nhân tình? Thế là hèn, là xấu, là không có đức hạnh gì cả, không có thông minh nhan sắc gì cả, nên chẳng ma nào nó thèm chim! Nếu tôi không có nhân tình thì bạn hữu tôi sẻ khinh bỉ tôi, tôi còn sống với đời sao được? Có ăn có chọi mới gọi là trâu chứ? Thế mà tôi cũng giữ trinh tiết với mình, không có ai là nhân tình thứ hai nữa, thì mình nên cho là hạnh phúc rồi!” (Vũ, 2014, tr. 146147). Sư Tăng Phú làm kinh tế để chống lại Hội Phật giáo: "Ông này cũng tân thời Âu hóa theo văn minh vì ông có ba cái răng vàng trong mồm, cái áo lụa Thượng Hải nhuộm nâu, đi đôi dép láng đế cao su, và nhất là đẹp giai lắm, trông phong tình lắm” (Vũ, 2014, tr. 201). Cô Tuyết, bà Phó Đoan, cụ cố Hồng, Sư Tăng Phú, Joseph Thiết, bác sĩ Trực Ngôn... tất cả đều nhằm chuyển tải hồi chuông cảnh báo cho sự xuống cấp đạo đức của lối sống giả tạo, văn minh rởm. Biểu tượng Âu hóa mà Vũ Trọng Phụng sử dụng chỉ là mỹ từ nhằm biện minh cho những sự xuổng cấp đạo đức.

Bằng những hành động của con người trong những trạng huống, tình huống, Vũ Trọng Phụng đã vẽ nên xã hội băng hoại, xấu xa, gớm ghiếc, làm biến chất con người với thế lực đồng tiền, quyền lực. Tiểu thuyết Số đỏ là một xã hội mà con người lọc lừa, dối trá để leo lên những bậc thang danh vọng. Cả thế giới nhân vật đều dối trá, lừa gạt để mưu lợi ích cá nhân, vợ chồng Văn Minh và gia đình cụ cố Hồng đưa Xuân lên làm bác sĩ để nhằm chia gia tài của cụ cố, còn Xuân Tóc Đỏ khi ý thức được sự vô nghĩa lý của xã hội ưa nịnh hót, văn minh rởm đã lợi dụng và đạt được danh lợi. Cả ông Phán mọc sừng, họa sĩ TYPN, cô Tuyết, bà Phó Đoan, thầy bói,... cũng đều lừa gạt và dùng thủ đoạn để đạt được mục đích. Còn tiểu thuyết Giong tố là mô hình xã hội với sự thấp hèn, bất tín từ xã hội đến gia đình, cha con, vợ chồng, anh chị em.

Với mô hình tự sự ẩn ý - tượng trưng, người đọc có hứng thú khi khám phá ra ẩn ý đằng sau mỗi hình tượng nhân vật trong tác phẩm Vũ Trọng Phụng, bởi vì "Tượng trưng trở thành trung tâm của hệ thống hình tượng, sự kiện, thành sợi dây tổ chức sự kiện, hình tượng, tượng trưng có ẩn ý phong phú” (Đỗ, 2015, tr. 218). Chẳng hạn như hình tượng cậu Phước (Em chã) trong Số đô, mặc dù chỉ xuất hiện thoáng qua hai lần nhưng đã để lại ấn tượng sâu đậm của một cậu bé con giời với căn bệnh tuổi dậy thì sớm; Hoặc hình tượng cảnh sát Min-đơ, Min-toa là những tay đua xe đạp kiệt xuất; Bác sĩ Trực Ngôn với lý thuyết Phân tâm học của Freud nhưng lại nể phục vài câu phán bừa của Xuân; Cậu học trò người yêu của Tuyết lại hoảng sợ khi nghe bài vè quảng cáo 
thuốc của Xuân hay những đám đông đưa tang cụ tổ; Những đám đông nghe Xuân phát biểu và tán thưởng Xuân như nhà chính trị đại tài. Những hình tượng này một mặt chuyển tải nội dung tư tưởng và chủ đề của tác phẩm, mặt khác còn là mối liên kết chặt chẽ tạo ra một hệ thống, mang tính chỉnh thể của tiểu thuyết $S o ̂ ́$ đỏ.

\section{THỦ PHÁP CÁT DÁN ĐIỆN ẢNH}

Vào đầu thế kỷ XX, những thành tựu khoa học kỹ thuật và thương mại đã làm xuất hiện nhiều loại hình nghệ thuật mới như điện ảnh, nhiếp ảnh. Các loại hình nghệ thuật như hội họa, kiến trúc, điêu khắc, văn học, âm nhạc cũng ứng dụng những kỹ thuật và chất liệu mới từ thành quả của sự phát triển khoa học kỹ thuật. Ngoài ra, các loại hình nghệ thuật còn tương tác lẫn nhau trong sáng tạo. Chẳng hạn như, văn học hiện đại chủ nghĩa có thể sử dụng kỹ thuật, thủ pháp của những loại hình nghệ thuật mới như hình ảnh, tạo hình, bố cục của kiến trúc, nhiếp ảnh, điêu khắc khi tiếp cận hiện thực; Kỹ thuật cắt dán của điện ảnh khi xây dựng cốt truyện. Chủ nghĩa hiện đại hướng đến phá vỡ ranh giới giữa các loại hình nghệ thuật để tìm kiếm những cách thức biểu đạt mới.

Mối quan hệ giữa loại hình nghệ thuật điện ảnh và văn học mang tính chất hai chiều. Điện ảnh lấy cảm hứng và chất liệu từ văn học, ngược lại, văn học tiếp thu các thủ pháp sử dụng trong điện ảnh. Thủ pháp cắt dán điện ảnh (montage) thường được sử dụng nhằm kể lại, mô phỏng lại một câu chuyện bằng cách xáo trộn biến cố sự kiện, không gian, thời gian hoặc lồng ghép nhiều câu chuyện, nhiều loại nhân vật. Ngoài ra, các điểm nhìn trần thuật còn có sự di chuyển cùng lúc trên nhiều nhân vật. Tương tự kỹ thuật dựng phim trong điện ảnh, các hình ảnh hiện thực đời sống được mô phỏng một cách chi tiết, tỉ mỉ và sau đó được dàn dựng lại theo ý đồ của đạo diễn. Với kỹ thuật này, những hình ảnh chi tiết, tỉ mỉ được mô tả trong tác phẩm khiến cho người đọc trải nghiệm cùng với nhân vật chứ không phải nhìn từ bên ngoài. Thủ pháp này còn khiến cho người đọc tin vào truyện kể chứ không phải tin vào người kể. Nhiểu nhà văn phương Tây sử dụng thủ pháp cắt dán điện ảnh, đặc biệt là trong tiểu thuyết dòng ý thức. Tiểu thuyết Người tình của Marguerite Duras là tiểu thuyết sử dụng thủ pháp này khi cấu trúc phân cảnh, hình ảnh và cả âm thanh. Ở phương Đông, Mạc Ngôn là một trong những nhà văn thành công khi sử dụng thủ pháp cắt dán điện ảnh trong các tiểu thuyết Cao lương đỏ, Rùng xanh lá đỏ,...

Trước khi phân tích về thủ pháp cắt dán điện ảnh theo trào lưu chủ nghĩa hiện đại, cần phân tích điểm nhìn trần thuật trong tác phẩm của Vũ Trọng Phụng. Trong một số truyện ngắn và kịch bản đầu tay, Vũ Trọng Phụng đặt điểm nhìn trần thuật bên trong, tức là trần thuật bằng quan điểm của nhân vật, người kể chuyện bao quát và dẫn dắt toàn bộ câu chuyện, mang tính luận đề. Đến Số đỏ, Giông tố và một số truyện ngắn khác, Vũ Trọng Phụng đặt điểm nhìn trần thuật bên ngoài. Người kể chuyện chỉ khách quan kể lại các biến cố, sự kiện, hành động của các nhân vật. Phương $(2015$, tr. 195) trong bài nghiên cứu Vấn đề phân loại góc nhìn trần thuật (Trích bút ký Tự sụ học), đề nghị nên sử dụng tên gọi là phi tiêu điểm theo ý kiến của nhà nghiên cứu Genette. Khi bàn về Điểm nhìn trần thuật trong văn xuôi hu cấu, Huỳnh $(2017$, tr. 71$)$ trong công trình Tác phẩm và thể loại văn học, gọi đó là tiêu cự ngoại quan (focalisation externe): 
Đây là cái nhìn bên ngoài, từ đó người trần thuật đề cập đến những gì mà người ấy có thể quan sát từ bên ngoài qua hành vi của các nhân vật mà không bình luận, giải thích hay đi vào thế giới nội tâm của nhân vật. Có thể xem đó là những truyện kể có tính chất hành vi luận (behaviourism), trong đó người trần thuật biết về các nhân vật ít hơn là các nhân vật biết về chính nó, vì vậy, mọi sự phân tích tư tưởng và tình cảm của nhân vật hầu như bị loại trừ trong văn xuôi.

Hầu hết tiểu thuyết Tự Lực Văn Đoàn đều đặt điểm nhìn trần thuật bên trong. Đến Nam Cao, mặc dù giọng điệu lạnh lùng, vô cảm nhưng cũng đặt điểm nhìn bên trong, thường là đặt điểm nhìn vào một nhân vật trong truyện hoặc người kể chuyện xưng Tôi. Trong khi đó, Vũ Trọng Phụng lại đặt điểm nhìn bên ngoài chỉ ghi lại, thuật lại hành động của nhân vật, biến cố của sự kiện, ít thể hiện quan điểm, thái độ. Đặc biệt là trong các tiểu thuyết Số đỏ, Giông tố và các truyện ngắn Thu đoạn, Cô Mai thuoơnng xuân, Bộ răng vàng, Bà lão lòa,... điểm nhìn bên ngoài đã được Vũ Trọng Phụng sử dụng một cách có hiệu quả.

Ở một số tác phẩm, điểm nhìn bên ngoài này còn là góc nhìn biết hết với nhiều sự chọn lựa, tức là người trần thuật vẫn ở bên ngoài nhưng dựa trên quan điểm của nhiều nhân vật để tạo góc nhìn bên trong. Chẳng hạn như sự kiện Mịch bị hiếp dâm bởi Nghị Hách trong tiểu thuyết Giông tố. Mở đầu tiểu thuyết, người trần thuật đứng bên ngoài mô tả lại sự kiện với thái độ khách quan gồm "Đó là một người gần 50 tuổi" (Vũ, 2000, tr. 150), "Chị nhà quê" (Vũ, 2000, tr. 155) trong bối cảnh "Giữa lúc đêm khuya tĩnh mịch" (Vũ, 2000, tr. 149). Khi đến huyện đường, điểm nhìn trần thuật lúc này chuyển sang nhân vật Nghị Hách:

Bảo hiếp dâm thì thật là vu oan. Thưa ngài, lúc ấy xe hơi của chúng tôi liệt máy, phải chữa trong hai ba tiếng đồng hồ. Giữa lúc tôi buồn, thình lình con bé ấy dẫn xác đến. Ngài cũng thừa biết cho là dẫu người tai to mặt nhớn đến thế nào đi nữa, thì cũng phải có lúc giăng gió một chút, cái ấy là trời sinh ra. Tôi hỏi con bé, nó đã bằng lòng... nó cũng như là một đứa giang hồ, mà cái việc xằng bậy của tôi thì cũng chỉ là của một người không hoàn toàn đứng đắn mà đi chơi bậy đêm mà thôi (Vũ, 2000, tr. 202).

Sau đó, đến khi quan huyện mới xử vụ án hiếp dâm, thì điểm nhìn lại được di chuyển, đưa đến một góc nhìn khác:

Mày là đứa hư nhé! Một người lại là đàn ông, đã không là ông mày, không là bố mày, không là chú, bác, anh, em họ hàng, thân thuộc nhà mày mà đi thương mày, thì chỉ là muốn ngủ với mày mà thôi. Thế mà mày đã nhận tiền! Mày như thế là hư lắm (Vũ, 2000, tr. 238).

Vũ Trọng Phụng sử dụng góc nhìn phi tiêu điểm với nhiều chọn lựa nhằm đưa đến cái nhìn đa diện. Mặt khác, Vũ Trọng Phụng còn chủ tâm đưa đến lý thuyết tương đối khi nhìn nhận sự việc, hiện tượng. Tức là một sự việc có thể có nhiều cách lý giải hợp lý khác nhau. Đặc biệt, trong hoàn cảnh xã hội lúc bấy giờ, cách lý giải thị Mịch bán thân lấy tiền không phải không hợp lý. Điều này cho thấy quan điểm của Vũ Trọng 
Phụng mang tinh thần của Thuyết tương đối Albert Einstein theo trào lưu hiện đại chủ nghĩa. Thuyết tương đối của Albert Einstein đề xuất năm 1905, cho rằng, cùng một hiện tượng nhưng có thể cho ra những kết quả khác nhau nếu nhìn từ hệ quy chiếu khác nhau.

Để rõ hơn, có thể nêu dẫn chứng cái chết của cụ tổ nhà cụ cố Hồng không phải là điều đáng buồn trong con mắt của bọn người hám lợi, "Cái chết của ông lão già đã làm cho nhiều người sung sướng lắm" (Vũ, 2014, tr. 224). Với góc nhìn biết hết với nhiều sự chọn lựa này, Vũ Trọng Phụng đã lột mặt nạ, hay nói cách khác là vạch mặt mọi sự giả dối, bao biện, che đậy của làn sóng Âu hóa trong tiểu thuyết Số đỏ. Một số dẫn chứng khác là hình tượng cậu Phước (Em chã) được khắc họa với miêu tả tỉ mỉ chi tiết từ bên ngoài qua lời của người trần thuật:

Trong cái chậu thau khổng lồ, một cậu bé to tướng béo mũm mĩm, mặt trông ngẩn ngơ, giá đứng lên thì ít ra cũng cao lớn hơn một thước tây, ngồi vầy nước như một đứa trẻ lên ba. Chung quanh cái chậu thau có vô số đồ chơi bày la liệt. Nào là con chó bông, con búp bê, cái ô tô, cái tàu bay, cái kèn... (Vũ, 2014, tr. 44-45).

Còn trong mắt bà Phó Đoan, đó là đứa con giời, con Phật, cần được cưng chiều, cung phụng, "Chiều hôm qua, cậu Phước hắt hơi ba lần... Đến tối, sau khi uống nước, cậu lại nấc. Đêm đến cậu chỉ đái dầm có một bận chứ không phải hai bận như mọi đêm. Sáng sớm hôm nay, cậu lại ho ba tiếng." (Vũ, 2014, tr. 187). Ngược lại, bọn gia nhân trong nhà chỉ cho rằng đó là cậu bé bình thường đến tuổi dậy thì được tẩm bổ khí huyết cho phương cương mà thôi:

Những lúc nó cứ "em chã” rồi vạch yếm vú em ra mà sờ vú rồi lại giả vờ bú ấy! Thế là dâm đến nơi cũng như mẹ nó, chứ không thì còn là cái cóc khô gì! Nhất là những lúc nó bắt vú em cõng nó rồi nó nhong nhong cưỡi ngựa đủ biết! Rau nào sâu ấy, phương ngôn đã có câu... (Vũ, 2014, tr. 194-195).

Còn nhiều hình tượng nhân vật khác cũng bị lột mặt nạ như ông Phán mọc sừng muốn mọc sừng một cách ồn ào để được chia thêm tài sản, cô Tuyết học đòi vắn minh bằng cách làm gái trinh một nửa, ông Văn Minh cổ vũ thể thao nhưng chưa bao giờ tập thể thao, bà Phó Đoan tiết hạnh khả phong với hai đời chồng, ông TYPN cải cách thời trang ngoài xã hội nhưng khắt khe với vợ con, sư Tăng Phú chủ báo tờ báo Gõ Mõ nhằm chống lại Hội Phật giáo.

Từ điểm nhìn bên ngoài, Vũ Trọng Phụng còn đã tái hiện hiện thực một cách khách quan trên trang văn. Nhờ đó, Vũ Trọng Phụng đã vô hiệu hóa những quan niệm chi phối tác phẩm như vấn đề giai cấp, tư tưởng hay quan điểm chủ quan của người trần thuật. Do đó, trên trang văn của Vũ Trọng Phụng, có thể thấy được tính dân chủ đối với mọi loại người, mọi hạng người trong xã hội. Từ giàu sang đến nghèo hèn, từ tri thức đến nông dân, cả trai gái, già trẻ đều có những cái xấu, cái ác. Con người với cái phi nhân, bản năng vô thức trong những trạng huống, hoàn cảnh, tình huống đều bộc lộ sự tham lam, đê hèn, dâm dục, lọc lừa. 
Điểm nhìn trần thuật này còn hỗ trợ đắc lực cho thủ pháp cắt dán điện ảnh theo trào lưu hiện đại chủ nghĩa. Góc nhìn bên ngoài này phù hợp để đặt con mắt camera ghi chép một cách trung thực hiện thực đời sống. Trước tiên, con mắt camera đã được sử dụng một cách triệt để khi thì ghi lại hình ảnh bao quát (long shot), khi thì đặc tả chi tiết, tỉ mỉ (close up). Chẳng hạn, Vũ Trọng Phụng dành hai trang chỉ để miêu tả từng góc nhỏ của cái ấp Tiểu vạn trường thành của nhà triệu phú Tạ Đình Hách:

Cái ấp của nhà triệu phú Tạ Đình Hách thật là đồ sộ nhất tỉnh, đến dinh quan Công sứ cũng không to tát bằng. Ấp ở cách tỉnh lị năm cây số, làm trên một ngọn đồi cao một trăm thước, diện tích ước độ mười mẫu ta. Chung quanh ấp, nghĩa là sườn đồi, thì giồng toàn một giống cà phê, khiến cho khách bộ hành từ đằng xa đã thấy một quả núi nhỏ xanh đen mà trên ngọn là ba tòa nhà tây, tòa giữa thì ba tầng, hai tòa bên thì hai tầng, trông kiên cố và oai nghiêm như một trại binh vậy. Điểm lơ thơ bên cạnh những tòa nhà ấy, là những cây gạo, cây muỗng cổ thụ, những cây ngô đồng và những cây thông. Chung quanh ba tòa nhà có vườn hoa thì một vòng tròn rào găng cao tới hai đầu người và dày độ hai thước. Cổng chính của ấp, xây bằng xi măng cốt sắt, là một cái thể môn kiểu Nhật Bản trên có đề bốn chữ nó tỏ rõ cái linh hồn ông chủ: Tiểu vạn trường thành. Từ cổng ấp, nghĩa là từ lưng chừng đồi mà xuống đến đường quan lộ, thì có một con đường nhỏ cũng rải đá và đổ nhựa kỹ càng cũng như đường thuộc địa (Vũ, 2000, tr. 169).

Hầu hết các nhân vật chính hoặc một số nhân vật phụ đều được Vũ Trọng Phụng đặc tả chi tiết, tỉ mỉ đầu tóc, quần áo, sắc thái, nhân tướng bằng con mắt camera. Sau khi ghi lại tất cả các cảnh trí, hình ảnh bằng con mắt camera ở góc nhìn biết hết nhiều lựa chọn, Vũ Trọng Phụng sẽ dàn dựng, sắp đặt có chủ ý để nhẳm chuyển tải nội dung mong muốn. Khảo sát văn bản Số đỏ hay Giông tố, thấy có một số đoạn bị cắt mất hoặc bị lược bỏ bớt vì không phục vụ cho chủ đề, tư tưởng của tác phẩm. Trong tiểu thuyết Giông tố, tình huống Nghị Hách, Tú Anh, Long được Hải Vân và Vạn Tóc Mai chỉ điểm bà Nghị đang ăn nằm với tên cung văn, mạch truyện lược bỏ quá trình cũng như cuộc gặp mặt. Tác phẩm chỉ kể lại tình huống bà Nghị bị bắt quả tang và những bí mật của cuộc đời Nghị Hách bị phanh phui.

Trong Số đỏ, có một số đoạn mạch truyện cũng bị gián đoạn khi chuyển giữa mỗi chương. Có thể, Vũ Trọng Phụng chỉ dàn dựng để mỗi chương phù hợp với tiêu đề đặt ra. Chẳng hạn, với tiêu đề ở chương Hạnh phúc của một tang gia - Văn Minh nữa cũng nói vào - Một đám ma gương mẫu, ở chương này chỉ tập trung những cảnh của đám tang cụ Tổ. Chương trước đó kết thúc bằng việc cụ cố tổ hấp hối và Xuân bỏ chạy ra khỏi nhà cụ cố Hồng. Người đọc không được biết Xuân đi đâu và làm gì, suy nghĩ gì mà chỉ thấy đột ngột xuất hiện cùng nhà sư Tăng phú để đi đưa đám cụ Tổ. Thay vào đó Xuân chỉ hiện lên qua những lời bàn bạc về việc có gả Tuyết cho Xuân hay không của gia đình Văn Minh. Vũ Trọng Phụng đã rất khéo léo khi cắt bỏ sự hiện diện của Xuân và chuyển điểm nhìn trần thuật sang những nhân vật khác.

Với thủ pháp cắt dán điện ảnh, Vũ Trọng Phụng có thể bao quát hiện thực cuộc sống ở diện rộng hơn. Mỗi tác phẩm của Vũ Trọng Phụng là một mảnh ghép cho bức 
tranh hiện thực đời sống rộng lớn. Khi đọc tất cả các tác phẩm của Vũ Trọng Phụng từ tiểu thuyết, truyện ngắn, đển kịch bản, có thể nhận thấy mối liên kết sự kiện giữa các tác phẩm. Chẳng hạn những nhân vật xuất hiện ở các tác phẩm khác nhau nhưng cùng kiểu loại như Cử Tân trong tác phẩm Lấy nhau vì tình và Làm đĩ đều là nhân vật bị tổn thương về mặt tình cảm nhưng giàu có nên có quan hệ tính giao với nhiều phụ nữ; Hàng loạt các nhân vật tiểu thư tân tiến, văn minh của các gia đình giàu có đều được đặt tên Tuyết, Vân như cô Tuyết trong Số đỏ, Tuyết và Vân con gái của Nghị Hách trong Giông tố, hoặc Tuyết Nương và Bạch Vân trong Hồ sê líu hồ líu sê sàng. Các tác phẩm như được chia tách hoặc tiếp nối nhau để trình bày nhiều phương diện, nhiều quan điểm như tiểu thuyết Dứt tình và truyện ngắn Cái hàng rào. Cả hai đều kể về tình duyên lận đận của Tiết Hằng không thể lấy người mình yêu nhưng tiểu thuyết Dưt tình khắc họa nỗi bất hạnh của Tiết Hằng khi sống trong cuộc hôn nhân môn đăng hộ đối, còn truyện ngắn Cái hàng rào kể về nguyên nhân bố của Hằng đi bước nữa với mẹ của người yêu Hằng. Vở kịch Cái chết bí mật của người trúng số độc đắc là đoạn kết nối dài của tiểu thuyết Trúng số độc đắc. Nhân vật Phúc ở cuối tiểu thuyết Trúng số độc đắc trở nên hoài nghi con người và đã rút ra bài học "loài người không ai tốt cả". Đến nhân vật Phúc trong vở kịch Cái chết bí mật của người trúng số độc đắc thì tự tử vì nghi hoặc cả chính bản thân mình:

Em nên hiểu rằng khi người ta có trong tay số tiền mười vạn thì một cái gương cũng có thể biết nịnh hót và huyễn hoặc người ta được lắm! Ấy thế là anh ta nghi ngờ nốt cả cái gương, bảo thế nào, anh ta cũng không nghe ra, cứ nhất định tin rằng mặt mình hóa ra mặt của kẻ tù tội (Vũ, 2000, tr. 247).

Khi đọc các tác phẩm Giông tố, Trúng số độc đắc, Lấy nhau vì tình, Thủ đoạn, Bẫy tình,... Vũ Trọng Phụng có miêu tả một số đoạn về nhà săm, gái giang hồ. Đến tiểu thuyết $L a ̀ m$ đĩ, nhà văn này lại đưa đến một cái nhìn khác về những thân phận phụ nữ làm gái giang hồ. Vũ Trọng Phụng còn sử dụng tác phẩm này làm phản đề với tác phẩm kia. Nếu như tiểu thuyết Dít tình khắc họa nỗi bất hạnh của Tiết Hằng vì hôn nhân môn đăng hộ đối thì tiểu thuyết Lấy nhau vì tình lại mổ tả những mâu thuẫn xảy ra trong cuộc hôn nhân do thiếu lòng tin. Qua đó, Vũ Trọng Phụng đã đưa đến cái nhìn đa diện, len lỏi mọi góc khuất của bề mặt hiện thực để đánh giá, phán xét sự việc, hiện tượng.

\section{MộT VÀI GHI NHậN}

Trào lưu hiện đại chủ nghĩa luôn luôn tìm kiếm những hình thức nghệ thuật mới để đáp ứng nhu cầu diễn đạt trong văn học nghệ thuật. Do đó, trào lưu hiện đại chủ nghĩa bao gồm nhiều ý thức thẩm mỹ và khuynh hướng sáng tác xuất hiện liên tục, dồn dập. Với tư cách là một trong những nhà văn tiên phong tiểp nhận chủ nghĩa hiện đại, Vũ Trọng Phụng đã có những nỗ lực khi tiếp nhận cũng như chọn lựa những thủ pháp và kỹ thuật của trào lưu chủ nghĩa hiện đại trong tác phẩm. Đôi khi, Vũ Trọng Phụng vẫn còn vụng về khi sử dụng những thủ pháp nghệ thuật theo trào lưu hiện đại chủ nghĩa nhưng đó là những nỗ lực đáng trân trọng của một nhà văn mang sứ mệnh hiện đại hóa nền văn học dân tộc. 
Bên cạnh các nhà Thơ Mới, một trong những nhà văn góp phần lớn tiếp thu và vận dụng chủ nghĩa hiện đại là Vũ Trọng Phụng. Theo như ghi chép của các tài liệu trên báo chí đương thời, Vũ Trọng Phụng có ý thức và sẵn sàng cho việc tiếp nhận chủ nghĩa hiện đại. Nhà văn này còn lớn lên và sinh sống trong môi trường đô thị có những biến đổi mau lẹ và sâu sắc những năm nửa đầu thế kỷ XX đã hình thành nhãn quan đô thị nhãn quan logic và đa chiều. Tuy Vũ Trọng Phụng phản ứng có phần gay gắt khi đứng trước làn sóng văn minh Âu hóa nhưng đó là sự tiếp nhận có ý thức và có chiều sâu. Theo chúng tôi, "tri giác đô thị” của Vũ Trọng Phụng đã góp phần cho việc tiếp nhận và vận dụng chủ nghĩa hiện đại vào trong sáng tác.

Vũ Trọng Phụng tiếp thu chủ nghĩa hiện đại như là sự bù đắp cho những khiếm khuyết của chủ nghĩa hiện thực, chủ nghĩa tự nhiên. Nếu chủ nghĩa hiện thực và chủ nghĩa tự nhiên chú trọng phản ảnh bề mặt của hiện thực đời sống thì chủ nghĩa hiện đại nhấn mạnh nguyên nhân sâu xa đằng sau bề mặt hiện thực. Cùng một sự kiện, hiện tượng nhưng Vũ Trọng Phụng đưa đến cho người đọc nhiều quan điểm, thái độ và cách lý giải khác nhau. Vũ Trọng Phụng không nhìn sự việc, hiện tượng một phía mà cầm nó lên, xoay ngang, xoay dọc để phản ánh một cách hiện thực nhất.

Đối với phương thức tiếp cận hiện thực, Vũ Trọng Phụng đã có những cách tân đáng kể so với các nhà văn hiện thực đương thời. Qua Số đỏ, Giông tố và một số truyện ngắn, kịch ngắn, Vũ Trọng Phụng sử dụng phương thức phản ánh hiện thực độc đáo qua mô hình tự sự ẩn ý - tượng trưng và thủ pháp cắt dán điện ảnh. Chủ nghĩa hiện đại không chỉ hỗ trợ cho phương thức tiếp cận hiện thực của chủ nghĩa hiện thực qua mô hình tự sự ẩn ý - tượng trưng mà còn mở rộng diện nhìn, vươn tới đằng sau bề mặt hiện thực. Mặc dù, thủ pháp cắt dán điện ảnh khiến cho tác phẩm của Vũ Trọng Phụng bị xem là dàn dựng theo ý muốn chủ quan của tác giả chứ chưa mô phỏng khách quan hiện thực đời sống. Nhưng thế giới trong tác phẩm của Vũ Trọng Phụng lại tái hiện chân thực đến mức người đọc tin và tìm thấy mẫu hình của Xuân Tóc Đỏ, bà Phó Đoan hay TYPN ngoài đời. Nhiều nhà nghiên cứu còn cho rằng, rất có thể, nguyên mẫu của bà Phó Đoan là bà me Tây Bé Tý ở Hàng Bạc, nhà thiết kế TYPN là họa sĩ Nguyễn Cát Tường với kiểu quần áo tân thời Lemur, nhà sư Tăng Phú chủ bút tờ Gõ Mõ là Nguyễn Năng Quốc chủ nhiệm tờ Đuốc Tuệ,... Nhà nghiên cứu Trần (2002, tr. 26) trong Cá tính sáng tạo và đặc điểm tiểu thuyết hiện thực của Vũ Trọng Phụng đã khẳng định sự độc đáo của phương thức tiếp cận hiện thực trong tác phẩm của Vũ Trọng Phụng khi so sánh với Nam Cao:

Với một cảm quan hiện thực sắc sảo và tinh nhạy, Vũ Trọng Phụng đã cảm nhận sâu sắc cái gọi là thế sự thăng trầm, trò đời đảo điên những diễ̂n biến phức tạp của thời cuộc. Nếu như tiểu thuyết của Nam Cao được dệt nên từ những cái hằng ngày thì tiểu thuyết của Vũ Trọng Phụng được tạo dựng từ những cái ngẫu nhiên, cái bất thường căng thẳng, đầy kịch tính, thể hiện sâu sắc sự bất ổn, nhố nhăng, hỗn loạn của thực tế xã hội.

So với bình diện tư tưởng và chủ đề, dấu ấn của chủ nghĩa hiện đại xét trên bình diện thi pháp trong tác phẩm của Vũ Trọng Phụng không đậm nét bằng. Hơn nữa, một số thủ pháp và kỹ thuật còn dung hòa cùng chủ nghĩa hiện thực, chẳng hạn như phương 
thức tiếp cận hiện thực. Dù vậy, Vũ Trọng Phụng cũng đã đạt được những thành công khi vận dụng những thủ pháp này trong các tác phẩm như Số đỏ, Bộ răng vàng, Thủ đoạn, Cô Mai thường xuân, Giông tố,...

\section{TÀI LIỆU THAM KHẢO}

Dettmar, K. J. H. (2006). Introduction. In D. Bradshaw, \& K. J. H. Dettmar, A companion to modernist literature and culture (pp. 1-5). New Jersey, USA: Blackwell Publishing Ltd.

Đỗ, V. H. (2015). Vận dụng lý thuyết tự sự học vào nghiên cứu hình thái thể loại tiểu thuyết. Trong T. Đ. Sử, Tư sụ học-Một số vấn đề lí luận và lịch sủ (Tập 2). Hà Nội, Việt Nam: NXB. Đại học Sư phạm.

Huỳnh, N. P. (2017). Tác phẩm và thể loại văn học. TP. Hồ Chí Minh, Việt Nam: NXB. Đại học Quốc gia TP. Hồ Chí Minh.

Lê, O. L., \& Nguyễn, N. Đ. (2015). Dẫn luận về tự sự học của Susanna Onega và J. A. García Landa. Trong T. Đ. Sử, Tư sự học-Một số vấn đề lí luận và lịch sủ (Tập 2). Hà Nội, Việt Nam: NXB. Đại học Sư phạm.

Phương, L. (2015). Vấn đề phân loại góc nhìn trần thuật. Trong T. Đ. Sử, Tư sự học Một số vấn đề lí luận và lịch sư (Tập 2). Hà Nội, Việt Nam: NXB. Đại học Sư phạm.

Trần, Đ. S. (2002). Cá tính sáng tạo và đặc điểm tiểu thuyết hiện thực của Vũ Trọng Phụng. Tạp chí Văn học, (10), 22-28.

Vũ, T. P. (2000). Toàn tập (Tập 2). Hà Nội, Việt Nam: NXB. Hội Nhà văn.

Vũ, T. P. (2000). Toàn tập (Tập 3). Hà Nội, Việt Nam: NXB. Hội Nhà văn.

Vũ, T. P. (2014). Số đỏ. Hà Nội, Việt Nam: NXB. Hội Nhà văn.

Vương, T. N. (1990). Một lớp người thành thị, một kiểu nhà văn - Trường hợp Vũ Trọng Phụng. Tạp chí Văn học, (43), 25-35.

Zinoman, P. (2001). Số đỏ của Vũ Trọng Phụng và chủ nghĩa hiện đại Việt Nam. Tạp chí Văn học, (45), 103-125. 